\title{
Effect of Educational Intervention on Implementation of Neonatal Safety Standards
}

\author{
Syed M. Raza ${ }^{1} \quad$ Mohamed M. Sheta ${ }^{2}{ }^{-0} \quad$ Suzan S. Gad ${ }^{3} \quad$ Nermine Elmaraghy ${ }^{4}$ Ahmed S. Hussein ${ }^{5}$ \\ Shaimaa Sahmoud ${ }^{3}$ Abeer I. Al-Khalafawi ${ }^{6}$
}

1 Pediatrics and Neonatology Department, Sheikh Khalifa Medical City, Abu Dhabi, United Arab Emirates

2 Pediatrics and Neonatology Department, Mansoura General Hospital, Mansoura, Egypt

3 Pediatrics and Neonatology Department, Suez Canal University Faculty of Medicine, Ismailia, Egypt

${ }^{4}$ Microbiology and Immunology Department, Suez Canal University

Faculty of Medicine, Ismailia, Egypt

${ }^{5}$ Pediatrics and Neonatology Department, Qantra Gharb General Hospital, Ismailia, Egypt

6 Pediatrics and Neonatology Department, Ras Elkheima Hospital, Ras Elkheima, United Arab Emirates
Address for correspondence Mohamed M. Sheta, MD, Pediatrics and Neonatology Department, Mansoura General Hospital, Mansoura 505005, Egypt (e-mail: sheta99999@yahoo.com).

J Child Sci 2020;10:e93-e96.

\begin{abstract}
Keywords

- patient safety

- Egyptian Neonatal Safety Standards

- neonatal intensive care unit

Background and Aim Patient safety in the neonatal intensive care unit (NICU) is one of the highest priority issues on the health care quality agenda worldwide. Efforts are needed to improve neonatal safety in NICU. The present study evaluated the effect of educational intervention on neonatal safety.

Materials and Methods Quasi-experimental study was conducted in three major hospitals, including the health care workers in their NICU during the period of study from May 2016 to May 2018. Neonatal safety standards were evaluated using an observational checklist after its validation by a pilot study. An intervention educational program was conducted in the three hospitals, followed by a reevaluation of the standards. All staff members ( 58 physicians and 69 nurses) participated in the three stages of the study. Results The interventional program resulted in significant improvement of the health care workers implementation of the general $(90.6 \pm 15.1 \mathrm{vs.} 127.6 \pm 7.02, p=0.016)$ and specific ( $50.6 \pm 17.1$ vs. $96.1 \pm 13.2, p=0.04)$ Egyptian Neonatal Safety Standards.

Conclusion Training and increasing the awareness of health care workers of the neonatal safety standards can significantly increase the fulfilment of these standards in both secondary and tertiary care neonatal units.
\end{abstract}

\section{Introduction}

Patient safety is the absence of accidental injury through the establishment of an operation process to minimize errors. ${ }^{1}$ Medical errors usually occur as a result of the failure of the planned action and/or using the wrong plan of action to achieve the goal. ${ }^{1}$ Medication errors happen due to inappro-

received

March 23, 2020

accepted after revision

July 24, 2020
DOI https://doi.org/ ISSN 2474-5871. 10.1055/s-0040-1716376. priate use of medication or as a result of inappropriate personal and or system approach, and this can be reduced by taking suitable preventive measures; thus, many organizations started to follow the safety standards to minimize the risk of error. ${ }^{2-4}$

Neonates are in specific need for error-free devices and instruments due to the immaturity of their immune system
Copyright @ 2020 Georg Thieme Verlag License terms
KG Stuttgart · New York 
and their prolonged hospitalization. ${ }^{5}$ The Egyptian Neonatal Safety Training Network (ENSTN) established the neonatal safety standards (NSS) to minimize the potential risks to patient safety in NICU. ${ }^{2}$ These standards help to eliminate the factors responsible for errors ${ }^{6}$ and familiarize the staff personnel with patient safety language. ${ }^{4}$ Unfortunately, there is a remarkable scarcity of patient safety programs that deal with neonatal and perinatal issues. ${ }^{7}$

Our work aimed at observing the fulfilment of the Egyptian NSS in three major hospitals in Ismailia, Egypt as well as reevaluating these measures after increasing the awareness of health care workers toward the neonatal safety.

\section{Materials and Methods}

This quasi-experimental study was conducted in three major hospitals in Ismailia Governorate, Egypt in the period from May 2016 to May 2018, involving Suez Canal University Hospital, Ismailia General Hospital, and Qantara Gharb Hospital. The study was approved by the Suez Canal University ethical committee (institutional review board approval no.162p/2016), and written consent was obtained from all the participants.

Implementation of NSS (general and specific) was evaluated using an observational checklist developed from the Egyptian NSS by ENSTN. ${ }^{2}$ Answers were scored 2 for complete fulfilment, 1 for partial fulfilment, and 0 for the absence of fulfilment of the standards. Prior to the implementation, the checklist was validated through a pilot study.

The preintervention observational stage was for 2 months, while the educational stage took almost 8 months during which multiple workshops and lectures were conducted in the target hospitals to provide basic ENSTN information.

The content of the educational materials was designed by the researchers and reviewed by experts in the neonatology, safety, and infection control. Collectively, three workshops and twelve 60 to 90 minutes lectures were performed. The postintervention stage was then pursued over another 2 months. All staff members (58 physicians and 69 nurses) participated in the three stages of the study. If one or more staff members missed a lecture or a workshop, the missed event was repeated.

\section{Statistical Analysis}

Data obtained from the present study were statistically analyzed using SPSS 20. Numerical variables were presented as mean and standard deviation. Paired $t$-test was used to compare pre- and postinterventional data. The $p$-value of less than 0.05 was considered statistically significant.

\section{Results}

Implementation of the educational program resulted in significant improvement of almost all general NSS. However, significant differences were achieved in standards 1, 2, 9, and 15 (-Table $\mathbf{1})$.
In addition, our intervention produced significant improvement of the specific NSS with significant improvement accomplished in standards $1,7,12$, and 16 (-Table 2). Moreover, the interventional program significantly improved total general standards score, the total specific standards score, and the total overall score ( - Table $\mathbf{3}$ ).

\section{Discussion}

In the present study, the interventional educational program for the NICU staff members results in significant improvement of the implementation of the NSS.

Neonatal safety in the ICU setting is the cornerstone of health care quality. Refining NSS require a thorough understanding of the systems involved in neonatal care delivery and continuous improvement of these systems. ${ }^{8}$ Unfortunately, many neonatal safety concerns are related to various human factors including miscellaneous forms of medical malpractice. ${ }^{9}$

Application of the scientific strategies and methods through education and training proved to be an efficient tool to boost human performance and reduce the risk of medical error, particularly in the sensitive and vulnerable neonatal population. ${ }^{10}$

In this context, the present study showed significant improvement in the implementation of the general and specific Egyptian NSS after an educational program.

The positive impact of training and education on health care professional practice in neonatal and pediatric ICU was acknowledged by a Brazilian study that noted significant improvement of various aspects of clinical practice including adherence to patient safety standards. ${ }^{11}$

Similarly, Murphy et al ${ }^{12}$ evaluated the effect of the teamwork and the communication training program on the safety attitude of 350 NICU staffs. They found that over 1 year of training, the safety attitude improved drastically. Arriaga Redondo et al ${ }^{13}$ concluded that using safety checklists in most of the health professional NICUs is very useful in avoiding adverse events.

Likewise, the study of Marofi et al ${ }^{14}$ assessed the effect of education and training program on rates of nosocomial infections (NIs) as a component of NSS. The authors reported a significant reduction in the rate of NIs related to improved implementation of safety standards after educational intervention.

Another evidence of the value of training comes from the recent work of Stadd et $\mathrm{al}^{15}$ who noted that staff education and training was associated with lower safety incidents related to the maternal practice of the kangaroo care.

The importance of training was also highlighted by the study of Mirlashari et $\mathrm{al}^{16}$ who identified the frequency of educational and training courses as a significant determinant of good competence of nurses regarding various aspects of neonatal care including NSS. Moreover, another study recognized the presence of well-trained professionals as a significant predictor of safe feeding practice in NICU. ${ }^{17}$ 
Table 1 Implementation of the general Egyptian Neonatal Safety Standards before and after the educational program in different hospitals

\begin{tabular}{|c|c|c|c|c|}
\hline $\begin{array}{l}\text { Standard } \\
\text { number }\end{array}$ & & Before & After & $p$-Value \\
\hline 1 & Providing high quality service care & $11.66 \pm 2.3$ & $14.66 \pm 3.2$ & 0.035 \\
\hline 2 & Person-centered care for newborn & $0.66 \pm 0.57$ & $3.66 \pm 1.15$ & 0.035 \\
\hline 3 & Timely care & $6.33 \pm 1.52$ & $9.0 \pm 1.0$ & 0.057 \\
\hline 4 & Improve the accuracy of newborn infants identification and prevent errors & $4.57 \pm 1.5$ & $4.57 \pm 1.5$ & 0.97 \\
\hline 5 & Improve the effectiveness of staff communications among NICU caregivers & $1.66 \pm 0.57$ & $2 \pm 0.12$ & 0.42 \\
\hline 6 & Use medicines safely in NICU & $8.3 \pm 3.5$ & $10.6 \pm 2.5$ & 0.073 \\
\hline 7 & Elimination of wrong site, wrong patient, and wrong procedures and surgery & $2 \pm 0.33$ & $3 \pm 0.5$ & 0.66 \\
\hline 8 & Reduced risk of health care acquired infections in NICU & $17.3 \pm 2.08$ & $23.3 \pm 1.15$ & 0.074 \\
\hline 9 & Reduce risk of newborn harm resulting from accidental fall during care & $0.57 \pm 0.3$ & $1.15 \pm 0.67$ & 0.048 \\
\hline 10 & Improve the safety of using infusion pump & $2 \pm 0.5$ & $2 \pm 0.5$ & 0.99 \\
\hline 11 & Use monitor alarms safely for patient stability & $4 \pm 1.1$ & $5.66 \pm 0.57$ & 0.19 \\
\hline 12 & $\begin{array}{l}\text { Accurately and completely reconcile medical care and medications across the } \\
\text { continuum of care of the newborn infants }\end{array}$ & $6.66 \pm 1.52$ & $9.33 \pm 1.15$ & 0.15 \\
\hline 13 & Ensure safety timely immunization. Reduce the risk of respiratory syncytial virus & $0.5(0.2)$ & $1.6(0.57)$ & 0.18 \\
\hline 14 & Reduce the risk of fires in NICU & $3 \pm 2.64$ & $5.6 \pm 1.52$ & 0.15 \\
\hline 15 & Identify patient safety risks/focused risk assessment & $0.5 \pm 0.2$ & $4.3 \pm 1.1$ & 0.023 \\
\hline 16 & Improve recognition and response to changes in a patient's condition & $1.33 \pm 0.57$ & $2 \pm 0.11$ & 0.18 \\
\hline 17 & Care of newborn infants must ensure the use of the well-functioning machines & $6.66 \pm 1.52$ & $8.66 \pm 2.08$ & 0.071 \\
\hline 18 & Utility system has to be maintained & $13 \pm 1.7$ & $15 \pm 1.1$ & 0.079 \\
\hline 19 & Measurement of neonatal care & $3.33 \pm 0.57$ & $3.66 \pm 1.15$ & 0.42 \\
\hline
\end{tabular}

Abbreviation: NICU, neonatal intensive care unit.

Table 2 Implementation of the specific Egyptian Neonatal Safety Standards before and after the educational program in different hospitals

\begin{tabular}{|c|c|c|c|c|}
\hline $\begin{array}{l}\text { Standard } \\
\text { number }\end{array}$ & & Before & After & $p$-Value \\
\hline 1 & Provide patient pathways & $8.33 \pm 2.3$ & $12.0 \pm 2.0$ & 0.032 \\
\hline 2 & Ensure safe transfer for newborn infants & $4.66 \pm 1.15$ & $5.6 \pm 1.5$ & 0.423 \\
\hline 3 & Care of the newborn immediately after birth & $3.33 \pm 0.58$ & $4.0 \pm 0.1$ & 0.18 \\
\hline 4 & $\begin{array}{l}\text { Newborn infants with low Apgar's score at } 5 \text { minutes should not go home till } \\
\text { checked by senior neonatologist }\end{array}$ & $2.0 \pm 0.1$ & $3.0 \pm 1.0$ & 0.22 \\
\hline 5 & Oxygen must be considered as serious drug when treating newborn infants & $5.66 \pm 1.15$ & $7.3 \pm 1.15$ & 0.13 \\
\hline 6 & Ensure safe invasive maneuvers when indicated for care of newborn infants & $2.33 \pm 1.52$ & $3.33 \pm 1.15$ & 0.42 \\
\hline 7 & Resuscitation of newborn infants by expert staff & $5.33 \pm 1.52$ & $6.66 \pm 1.15$ & 0.05 \\
\hline 8 & Encourage noninvasive ventilation in DR and in NICU & $2.0 \pm 0.1$ & $3.0 \pm 1.0$ & 0.225 \\
\hline 9 & Proper use of surfactant & $0.33 \pm 0.57$ & $0.66 \pm 1.15$ & 0.423 \\
\hline 10 & Judicious use of medications that have effect on quality of life & $0.66 \pm 0.57$ & $1.0 \pm 0.1$ & 0.423 \\
\hline 11 & $\begin{array}{l}\text { All newborn infants who have been admitted to NICU must subject to fundus } \\
\text { examination, hearing evaluation, and skull ultrasound before discharge }\end{array}$ & $0.66 \pm 0.57$ & $1.0 \pm 0.1$ & 0.423 \\
\hline 12 & Initiation of breastfeeding & $3.33 \pm 0.57$ & $6.0 \pm 0.23$ & 0.015 \\
\hline 13 & $\begin{array}{l}\text { Scheduling the optimum timing of discharge from NICU or nursery or other health } \\
\text { care facilities }\end{array}$ & $3.03 \pm 1.15$ & $3.33 \pm 0.57$ & 0.98 \\
\hline 14 & Prevent total parenteral nutrition errors & $2.33 \pm 2.5$ & $2.66 \pm 1.05$ & 0.423 \\
\hline
\end{tabular}


Table 2 (Continued)

\begin{tabular}{|c|c|c|c|c|}
\hline $\begin{array}{l}\text { Standard } \\
\text { number }\end{array}$ & & Before & After & $p$-Value \\
\hline 15 & $\begin{array}{l}\text { Improve the accurateness of respiratory care, resuscitation-related, and ventilator } \\
\text { care-related errors }\end{array}$ & $1.6 \pm 1.15$ & $2.5 \pm 0.57$ & 0.225 \\
\hline 16 & Prevent diagnostic errors among neonatal population & $5.0 \pm 1.73$ & $6.66 \pm 2.08$ & 0.038 \\
\hline
\end{tabular}

Abbreviations: DR, delivery room; NICU, neonatal intensive care unit.

Table 3 Overall implementation of Neonatal Safety Standards before and after educational intervention

\begin{tabular}{|l|l|l|l|}
\hline & Before & After & $p$-Value \\
\hline General standards score & $90.6 \pm 15.1$ & $127.6 \pm 7.02$ & 0.016 \\
\hline Specific standards score & $50.6 \pm 17.1$ & $96.1 \pm 13.2$ & 0.04 \\
\hline Total overall standards score & $141.3 \pm 32.1$ & $196.67 \pm 19.34$ & 0.021 \\
\hline
\end{tabular}

\section{Conclusion}

The present study shows the efficacy of the educational intervention on the implementation of the Egyptian NSS. Further studies are recommended to evaluate the influence of these interventions on the neonatal morbidity and mortality rates.

\section{Funding \\ None.}

\section{Conflict of Interest}

None declared.

\section{References}

1 Institute of Medicine Committee on Quality of Health Care in A. In: Kohn LT, Corrigan JM, Donaldson MS, eds. To Err Is Human: Building a Safer Health System. Washington (DC): National Academies Press (US); 2000

2 ELMeneza SA, Abu-Shady M, Weindling M, et al. Egyptian Neonatal Safety Standards. Egyptian Neonatal Safety Training Network; 2014

3 Food and Drug Administration (FDA), Department of Health and Human Services (DHHS). Code of federal regulations title 21: where can I find the reporting codes for adverse events that I use with medical device reports? Available at: https://www.accessdata.fda.gov/scripts/cdrh/cfdocs/cfcfr/CFRSearch.cfm?fr=803.21. Accessed January 14, 2016

4 Chatziioannidis I, Mitsiakos G, Vouzas F. Focusing on patient safety in the neonatal intensive care unit environment. Journal of Pediatric and Neonatal Individualized Medicine 2017;6(01):e060132 (JPNIM)

5 King A, Daniels J, Lim J, Cochrane DD, Taylor A, Ansermino JM. Time to listen: a review of methods to solicit patient reports of adverse events. Qual Saf Health Care 2010;19(02):148-157
6 Thomas EJ, Petersen LA. Measuring errors and adverse events in health care. J Gen Intern Med 2003;18(01):61-67

7 Agency for Healthcare Research and Quality Patient Safety Organizations. Available at: http://www.pso.ahrq.gov/listing/alphalist.htm. Accessed January 14, 2011

8 Gupta M, Soll R, Suresh G. The relationship between patient safety and quality improvement in neonatology. Semin Perinatol 2019; 43(08):151173

9 Fanaroff JM, Goldsmith JP. The most common patient safety issues resulting in legal action against neonatologists. Semin Perinatol 2019;43(08):151181

10 Yamada NK, Catchpole K, Salas E. The role of human factors in neonatal patient safety. Semin Perinatol 2019;43(08):151174

11 Bussotti EA, Leite MT, Alves AC, Cristensen K. Online training for health professionals in three regions of Brazil. Rev Bras Enferm 2016;69(05):981-985

12 Murphy T, Laptook A, Bender J. Sustained improvement in neonatal intensive care unit safety attitudes after teamwork training. J Patient Saf 2018;14(03):174-180

13 Arriaga Redondo M, Sanz López E, Rodríguez Sánchez de la Blanca A, et al. [Improving patient safety: usefulness of safety checklists in a neonatal unit]. An Pediatr (Barc) 2017;87(04):191-200

14 Marofi M, Bijani N, Abdeyazdan Z, Barekatain B. The impact of an educational program regarding total parenteral nutrition on infection indicators in neonates admitted to the neonatal intensive care unit. Iran J Nurs Midwifery Res 2017;22(06): 486-489

15 Stadd K, Diehl B, Yenokyan G, Aucott SW. A kangaroo care pathway for NICU staff and families: the proof is in the pouch. Adv Neonatal Care 2020;20(01):14-24

16 Mirlashari J, Qommi R, Nariman S, Bahrani N, Begjani J. Clinical competence and its related factors of nurses in neonatal intensive care units. J Caring Sci 2016;5(04):317-324

17 Matus BA, Bridges KM, Logomarsino JV. Evaluation of key factors impacting feeding safety in the neonatal intensive care unit: a systematic review. Adv Neonatal Care 2019;19(01):11-20 